\section{March madness}

The crowded field for this edition of marketplace includes new CD-ROMs, computer software, tools for PCR, and much, much more.

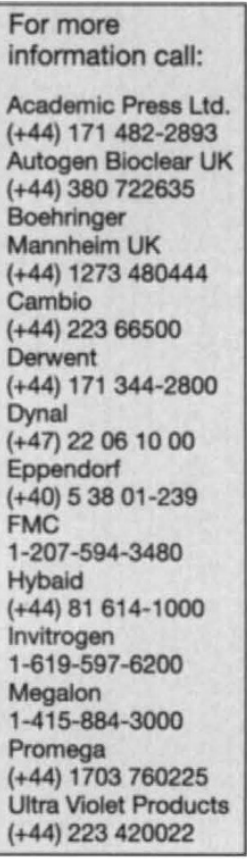

Two recently released CD-ROMs tip off this month's round-up of the latest product news. Derwent's Gene Therapy Database Sampler contains information on human gene therapy trials, including references from 1,200 journals, patent information from 37 countires, and abstracts from scientific conferences. Subscribers will receive a monthly updated database. Discounts are available for those who also wish to receive Derwent's Gene Therapy newsletter. Academic Press has launched Methods in Enzymology on CD-ROM. CD-1 is entitled 'Recombinant DNA and Related Methodology', and includes articles culled from 18 recent volumes on cloning, gene mapping, protein-DNA interactions and molecular evolution. CD-1 costs $£ 750$.

Megalon has released its first addon product for the ResearchStation ${ }^{\mathrm{TM}}$ scientific information management software launched latelast year. 'Plot \& 'Transform' is a powerful visualization component to enable columnar, matrix and image data to be analysed.

Ultra Violet Products (UVP) has introduced 'Grab-it', an image

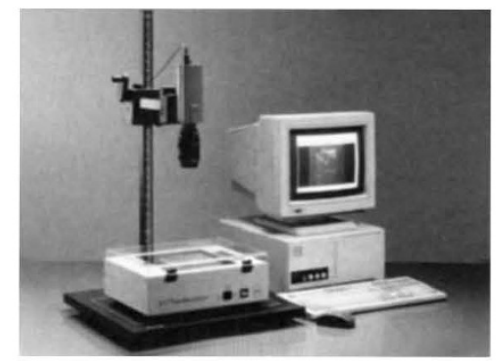

'Grab-it' from UVP.

manipulation and analysis system designed for use with an exisiting computer. The card is linked to a UVP camera, allowing images to be loaded into the computer and manipulated as required. In addition, the data can be analysed new UVP software such as GelBase Pro.

New products for the polymerase chain reaction (PCR) continue to multiply. Boehringer Mannheim has unveiled the Expand ${ }^{\mathrm{TM}}$ Long Template PCR system, designed to amplify genomic or phage DNA up to 30-40 kilobases, whilst reducing

transcription errors by $50 \%$. The system combines both Taq and Pwo polymerases, taking advantage of the replication efficiency of the former with the repairing potential of the

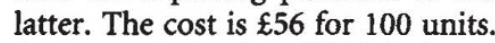
Invitrogen's HotWax ${ }^{\mathrm{TM}} \mathrm{Mg}^{2+}$ beads are designed to improve the speed and efficiency of Hot Start PCR. The beads release $\mathrm{MgCl}_{2}$ into the reaction during the first denaturation step, and the melted bead also forms an evaporation barrier to dispense with an oil overlay. For improved mRNA purification, Dynal provides a Dynabeads mRNA DIRECT kit, offering a simple 15 minute procedure to produce a quality template for reverse transcriptase-PCR. Using an oligo (dT) primer, poly(A) isolation is combined with the synthesis of the first strand cDNA. The immobilized cDNA library produced can be recovered and reused for multiple PCR amplifications.

On the hardware front, the new PCR Mastercycler plus is available from Eppendorf, featuring a heatable lid to avoid condensation problems. High incubating speeds enable run times of just one hour per experiment, and two blocks with separate controls allow different reactions to be run in parallel. Hybaid has produced a diminutive version of the OmniGene thermal cycler, called Omn-E, which is intended to be your own personal mini cycler. It comes with a choice of

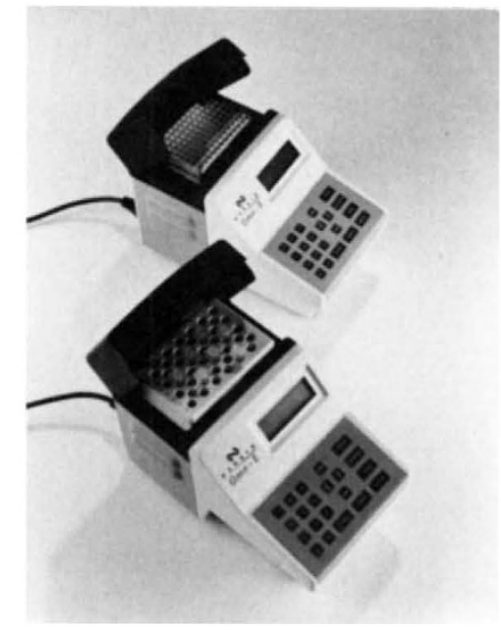

Hybaid's mini cyclers. heating blocks and the latest in thermistor probe technology.

Several new products are designed to improve the purification of DNA. Promega has introduce the new Wizard ${ }^{\mathrm{TM}}$ Genomic DNA purification kit, suitable for purifying DNA from whole blood. The procedure takes about 45 minutes, and yields about $10 \mu \mathrm{g}$ per $300 \mu \mathrm{l}$ sample, at less than $£ 1$ per preparation. FMC's MetaPhor ${ }^{\circledR}$ XR agarose forms flexible gels for high resolution ofDNA molecules less than $1 \mathrm{~kb}$, useful for mutation detection, providing the ease of agarose with the resolution of polyacrylamide. On a larger scale, the new AutoGen 740 from Autogen Bioclear is designed

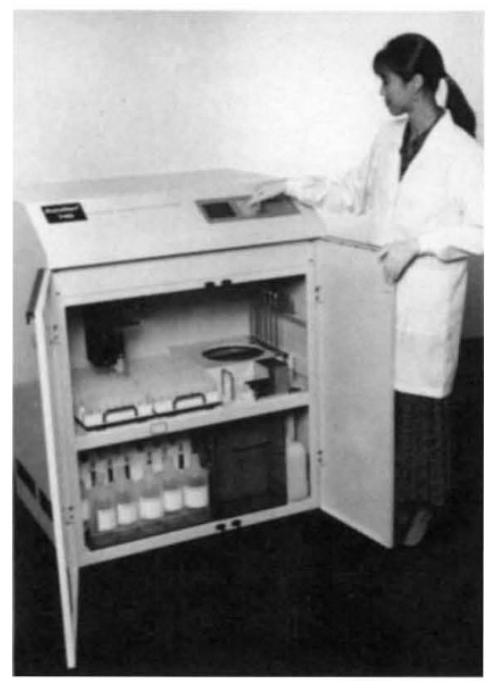

The AutoGen 740 .

for the high throughput isolation of many varieties of DNA, including plasmids, bacterial and yeast artificial chromosomes. Up to 160 samples may be purified in 16 hours.

For those with an interest in gender analysis and forensic testing, Promega hasprepared the Geneprint ${ }^{\mathrm{TM}}$ Sex Identification system, a rapidmethod of amplifying the amelogenin gene from the human $\mathrm{X}$ and $\mathrm{Y}$ chromosomes. This sensitive system relies on non-isotopic fluorescence or silver staining detection methods, suitable for samples containing less than $1 \mathrm{ng}$ of human DNA. Finally, Cambio is launching a DNA Damage kit, developed by Trevigen. The kit relies on the correlation between poly(ADP-ribose) polymerase (PADPRP), which plays an important roleinmodulating chromatinstructure close to regions of DNA repair, and the extent of DNA damage. Each kit is sufficient for 50 reactions. 